\title{
Expression of an activated ras gene causes developmental abnormalities in transgenic Drosophila melanogaster
}

\author{
John G. Bishop III and Victor G. Corces \\ Department of Biology, The Johns Hopkins University, Baltimore, Maryland 21218 USA
}

\begin{abstract}
We describe the developmental effects of the expression of a normal and mutated Drosophila ras gene ras 2 in transgenic Drosophila. A Gly14 $\rightarrow$ Val14 mutant (Gly14 in ras2 is equivalent to Gly12 in mammalian ras proteins) was constructed in ras 2 by site-directed mutagenesis. Inducible constructs of ras 2 and ras $2^{\text {val14 }}$ were made by coupling the hsp70 promoter to each of the genes. In addition, the endogenous ras 2 promoter was placed upstream of the mutated ras $2^{\text {val14 }}$. These constructs were introduced into the germ line of Drosophila to yield transgenic lines by P-element-mediated transformation. A wide variety of developmental disorders were displayed in flies carrying the mutated ras2 gene driven by either the endogenous or the hsp70 promoter. The basal level of transcription of mutated ras from the uninduced hsp70 promoter was sufficient to produce disturbances in the development of several tissue types. In contrast, phenotypic disturbances were not seen with the normal ras 2 gene driven by the hsp70 promoter even when induced by heat shock to very high levels of transcription over normal ras2 levels. A subset of the tissues expressing ras 2 during development was particularly sensitive to the expression of $\operatorname{ras} 2^{\mathrm{Val14}}$. The compound eye was found to develop a dorsal-to-ventral 'scar' correlated with the wave of differentiation occurring in the eye imaginal disc at the time of a single brief induction of the hsp70 promoted ras $2^{\text {Val14 }}$ construct.
\end{abstract}

[Key Words: ras; oncogenes; transgenic; site-directed mutagenesis; Drosophila; eye development]

Received February 16, 1988; revised version accepted April 4, 1988.

The ras proto-oncogenes have fundamental roles in normal and neoplastic cellular processes (reviewed in Barbacid 1987). Activated ras genes have been found in a substantial percentage of human tumors (Bos et al. 1987; Forrester et al. 1987) and arise experimentally in mouse tumors that have been induced by a variety of treatments such as gamma irradiation (Guerrero et al. 1984). The ras proteins bind guanine nucleotides, have GTPase activity, and are associated with the plasma membrane (Scolnick et al. 1979; Willingham et al. 1980; Gibbs et al. 1984; McGrath et al. 1984; Sweet et al. 1984; Willumsen et al. 1984; Manne et al. 1985; Temeles et al. 1985). Most amino acid substitutions in the ras protein at position 12 result in a lowered rate of GTP hydrolysis and a transforming (or activated) phenotype (Willingham et al. 1980; Gibbs et al. 1984; McGrath et al. 1984; Seeburg et al. 1984; Sweet et al. 1984; Willumsen et al. 1984; Chipperfield et al. 1985; Manne et al. 1985; Temeles et al. 1985). Sequence comparisons between ras and G proteins suggest that ras proteins act in transducing signals across the cellular membrane (Hurley et al. 1984; Lochrie et al. 1985; Tanabe et al. 1985). It has been found that ras proteins injected into mammalian cells cause a change in morphology, membrane ruffling, and increased pinocytosis (Bar-Sagi and Feramisco 1986).

Evolutionarily conserved ras genes have been found in yeast, slime mold, fish, mammals, plants, and Drosophila (Barbacid 1987). In yeast, gene disruption experi- ments have shown that ras proteins are involved in the regulation of growth and the activation of adenylate cyclase (Kataoka et al. 1984). The ras genes are expressed in both proliferating and terminally differentiated cells in Drosophila (Segal and Shilo 1986) and in humans (Chesa et al. 1987). Dictyostelium transformed with activated ras genes showed abnormal aggregation; wildtype ras genes had no affect (Reymond et al. 1986). In mammals, ras involvement in differentiation appears to be complex because injection of ras oncogenic protein has triggered morphological differentiation (neurite outgrowth) of PC12 cells (Bar-Sagi and Feramisco 1985), whereas the differentiation of a skeletal myoblast cell line can be prevented with the oncogenic forms of $\mathrm{H}$-ras and N-ras genes (Olsen et al. 1987). Transgenic mice carrying a MMTV LTR-promoted-v-ras construct showed in developmental aberration of a specific tissue, the Harderian gland, and tumors after varying latency periods (Sinn et al. 1987). The choice of promoter in these studies was of great importance because transgenic mice carrying the promoter for pancreatic elastase driving an activated ras gene developed pancreatic tumors with no latency (Quaife et al. 1987) while transgenic mice carrying the whey acidic protein gene promoter driving ras have a very low incidence of tumors (Andres et al. 1987).

We were interested in several questions involving ras genes and Drosophila. First, what phenotype(s) would 
evolve when a mutated form of ras is incorporated into the genome of an insect; would tumors or abnormal growth result? Second, if ras affects the normal development of a whole organism, would all tissues be affected in a similar manner or degree; would the sensitivity be time dependent? Third, what would be the consequence of an increased expression of the normal ras gene?

\section{Results}

Structure of the Drosophila ras2 locus

At the outset of these experiments, crucial information necessary for the construction of functional transforming ras genes was lacking. Partial genomic DNA sequences were available (Neuman-Silberberg et al. 1984; Mozer et al. 1985) and a preliminary Northern blot analysis indicated that three transcripts of 2.6, 2.1, and 1.6 $\mathrm{kb}$ originated from the ras region (Mozer et al. 1985). Did all three transcripts originate from the ras 2 gene or were they unrelated? As exogenous promoters were to be used to drive ras 2 transcription, the start of transcription of the ras 2 gene had to be defined more precisely. Because several potential polyadenylation sites had been recognized during the course of the genomic DNA sequencing, the determination of the processing site(s) actually used was essential for successful transformation experiments.
A detailed Northern blot analysis established that the larger transcripts are different from the ras 2 gene and map to the $5^{\prime}$ side of ras 2 . The analysis and sequencing of ras 2 cDNA clones revealed the probable transcription start site and the polyadenylation site of the ras 2 gene. The structure of the ras 2 gene obtained from genomic and cDNA sequencing, and Northern blot analysis is summarized in Figure 1. The $0.86 \mathrm{~kb} \mathrm{ClaI}$ fragment (Fig. 1B), mapping 55 nucleotides upstream of the putative ras 2 transcription start site (detailed below and Fig. 2), and extending in the $5^{\prime}$ direction from ras 2 sequences, hybridized only to the 2.6 and $2.1 \mathrm{~kb}$ RNA species on Northern blots (S. Parkhurst and V. Corces, unpubl.). On the other hand, the HindIII-BamHI fragment, comprising the bulk of the ras 2 coding region, contained in pUC8-HB-1.2 (Fig. 1B), hybridized to a single 1.7-kb RNA species. Segal and Shilo (1986) identified a 1.6-kb transcript using a similar probe. From these results, we conclude that the two large transcripts map close to the $5^{\prime}$ end of the ras 2 gene but are different from ras 2.

The two ras 2 cDNA clones depicted in Figure 1C revealed a potential transcription initiation site. The independent clones had identical $5^{\prime}$ terminal sequences and ended at the position marked 1 in Figure 2. A potential TATA sequence, GATATT, was found at position -55 in the genomic sequence. O'Connell and Rosbash (1984) found the same sequence at -51 from the start of transcription of the Drosophila ribosomal protein 49 gene. In

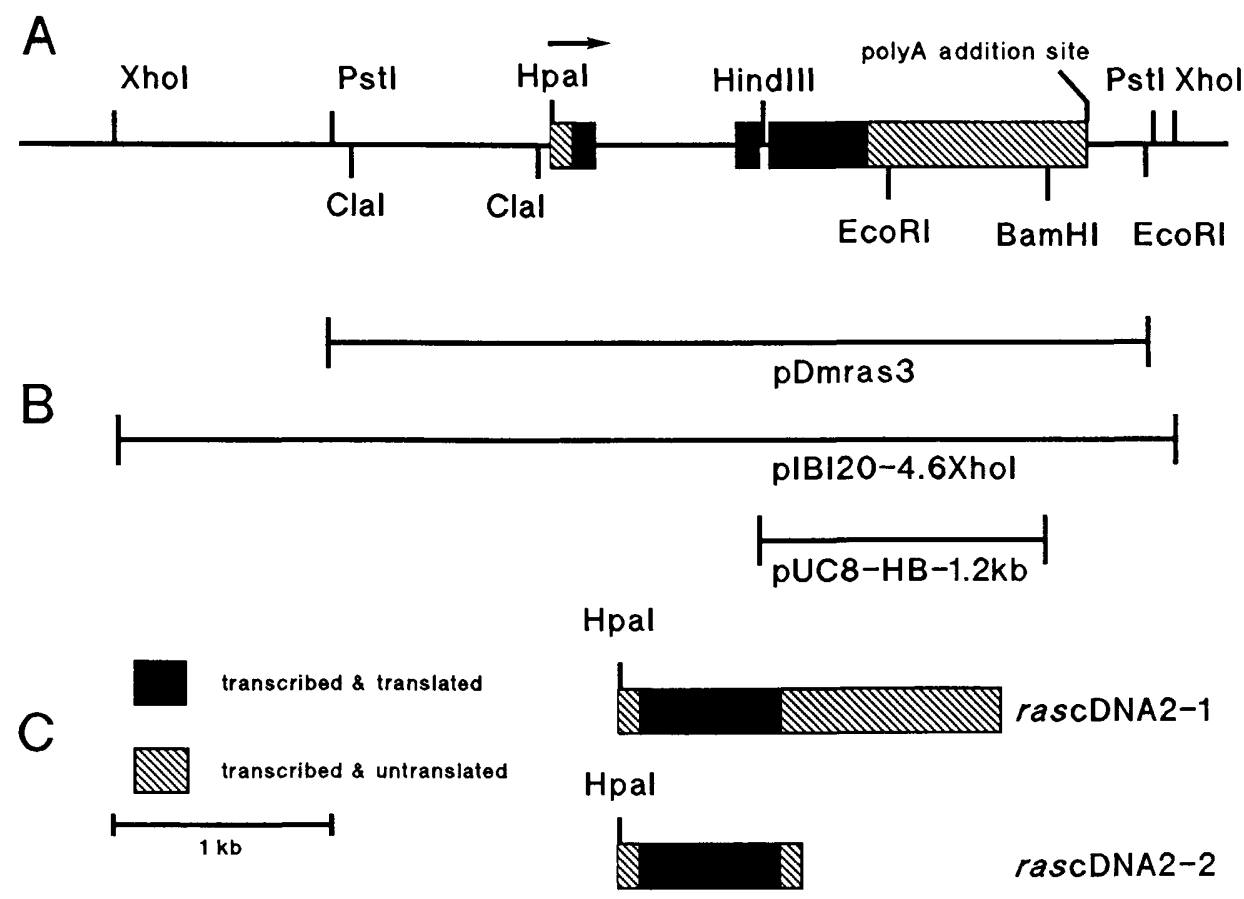

Figure 1. Scale drawings of the ras 2 genomic organization, subcloned fragments, and cDNA clones. $(A)$ A genomic restriction map of the ras 2 locus was determined from several subcloned genomic fragments. The arrow shows the direction of transcription of ras 2 . (B) Subcloned fragments used in this study. $(C)$ Two cDNA clones rascDNA2-1 and rascDNA2-2 of the ras 2 gene were isolated. Open reading frames were found in the sequence upstream of ras 2 in the opposite transcriptional orientation. No strong homologies were found with the conceptual polypeptides encoded therein and the BIONET protein database (Release 14). 


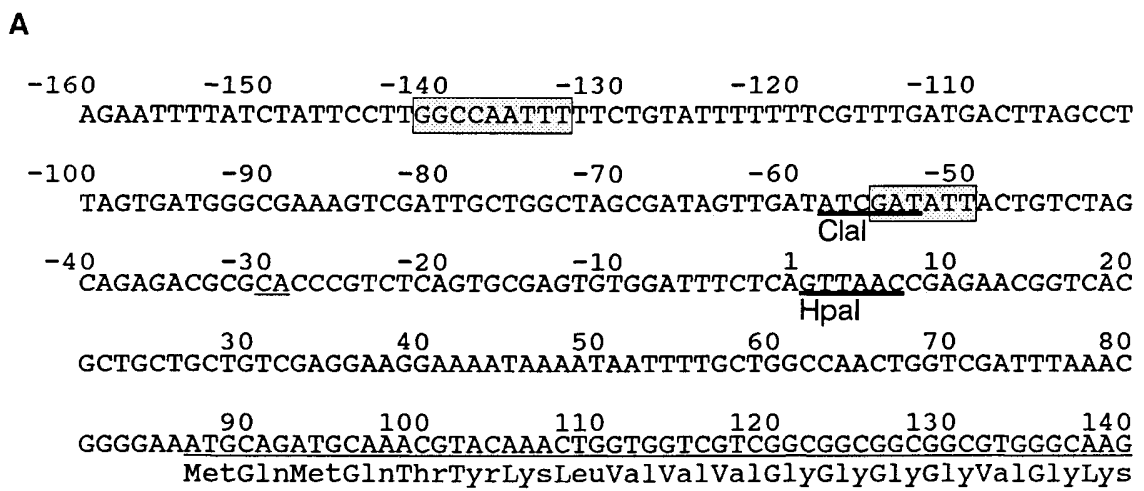

$\mathbf{B}$

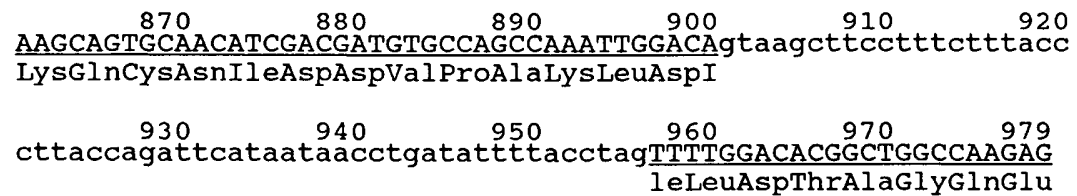

Figure 2. (A) Genomic DNA sequence of the promoter region of ras2. The putative CAAT sequence is boxed at position - 141 to -133 and the putative TATA sequence is boxed at position -55 to -50 (Corden et al. 1980). The first 18 codons of ras 2 are shown starting at position 87; the conceptual translated amino acid sequence is shown below the line. $(B)$ Genomic DNA sequence and predicted amino acid sequence of the exon 2-intron-exon 3 region of ras2. Numbering of positions was based on the cDNA clones $5^{\prime}$ termini; this is the putative mRNA start site. A putative second site at -29 is also underlined. Restriction sites are shown by heavy underlining. The cDNA sequence of the two ras cDNA clones revealed the splicing model of Mozer et al. (1985), based solely on genomic sequencing, required modification. The corrected splicing scheme and revised conceptual polypeptide sequence are shown. Intron sequences are shown in lower case.

addition, a eukaryotic CAAT sequence was discovered in the sequences immediately upstream of the ras 2 gene (Fig. 2).

One of the cDNAs was full length and allowed the identification of the processing site for polyadenylation. Clone rascDNA2-1 (Fig. 1C) ended in a polyadenylate sequence 36 nucleotides downstream from a polyadenylation signal sequence AATAAA (Proudfoot and Brownlee 1976). This was the most distal of the potential sites identified in the genomic sequencing; the other two lay 45 and 683 nucleotides closer to the ras 2 coding sequences. Functional transformation with ras 2 gene constructs would most likely require this polyadenylation signal and flanking sequences for proper processing. A ras 2 transcript of 1614 nucleotides, not including the polyadenylate tract, is predicted from the cDNA and genomic analysis, and was in close agreement with experimental results.

To obtain additional $5^{\prime}$ and $3^{\prime}$ sequences for the transformations with the ras 2 gene, a 4.6-kb Xhol ras 2 fragment was isolated from a Canton S library (Maniatis et al. 1978) and subcloned as pIBI20-4.6 XhoI (see Fig. 1B). The fragment contains $2 \mathrm{~kb}$ of sequence extending $5^{\prime}$ of the initiation codon and 400 nucleotides in the $3^{\prime}$ direction beyond the polyadenylation site.

\section{ras2 gene mutagenesis and P-element constructs}

The three constructs made for the present study are shown in Figure 3. The hsp70 promoter was coupled to the ras $24.6-\mathrm{kb}$ XhoI gene fragment at the $\mathrm{HpaI}$ site located 83 nucleotides upstream of the initiation codon of ras 2 gene and cloned into the P-element vector Carnegie20 (C20) (Rubin and Spradling 1983) to create C20-29 (Fig. 3A). Oligonucleotide-directed mutagenesis (Zoller and Smith 1983) was employed to create the mutation of Gly14 $\rightarrow$ Val14 /Gly14 in ras 2 is equivalent to Gly12 in mammalian ras proteins; Mozer et al. 1985) to create ras $2^{\text {Vall }}$; this $4.6-\mathrm{kb}$ Xhol fragment mutated at a single nucleotide was subcloned into $\mathrm{C} 20$ and named C20-35 (Fig. 3B). The ras $2^{\text {Vall4 }}$ gene construct was coupled to the hsp70 promoter at the HpaI site located 83 nucleotides upstream of the initiation codon of the ras $2^{\text {vall4 }}$ gene to create $\mathrm{C} 20-42$ (Fig. $3 \mathrm{C}$ ).

The $\mathrm{C} 20$ constructs with helper plasmid $\mathrm{p} \pi 25.7$ supplying transposase in trans were injected into rosy506 embryos with a Canton $\mathrm{S}$ background. These flies were mated to the $r y^{506}$ parental stock and their progeny scored for the presence of wild-type eye pigmentation indicating transformation with $\mathrm{C} 20$ which has a wildtype rosy gene. This protocol typically results in a single integrated copy of the gene of interest (Rubin and Spradling 1983). At least three separate lines were developed for each construct (see Table 1); each of these lines were crossed to chromosome balancer stocks with the dominant markers Curly on the second, Bar on the $\mathrm{X}$, or Stubble on the third chromosome to map the chromosomal location of the integrated transposon. Crosses to obtain homozygous stocks were done where possible; these results are shown in Table 1. 
Bishop and Corces

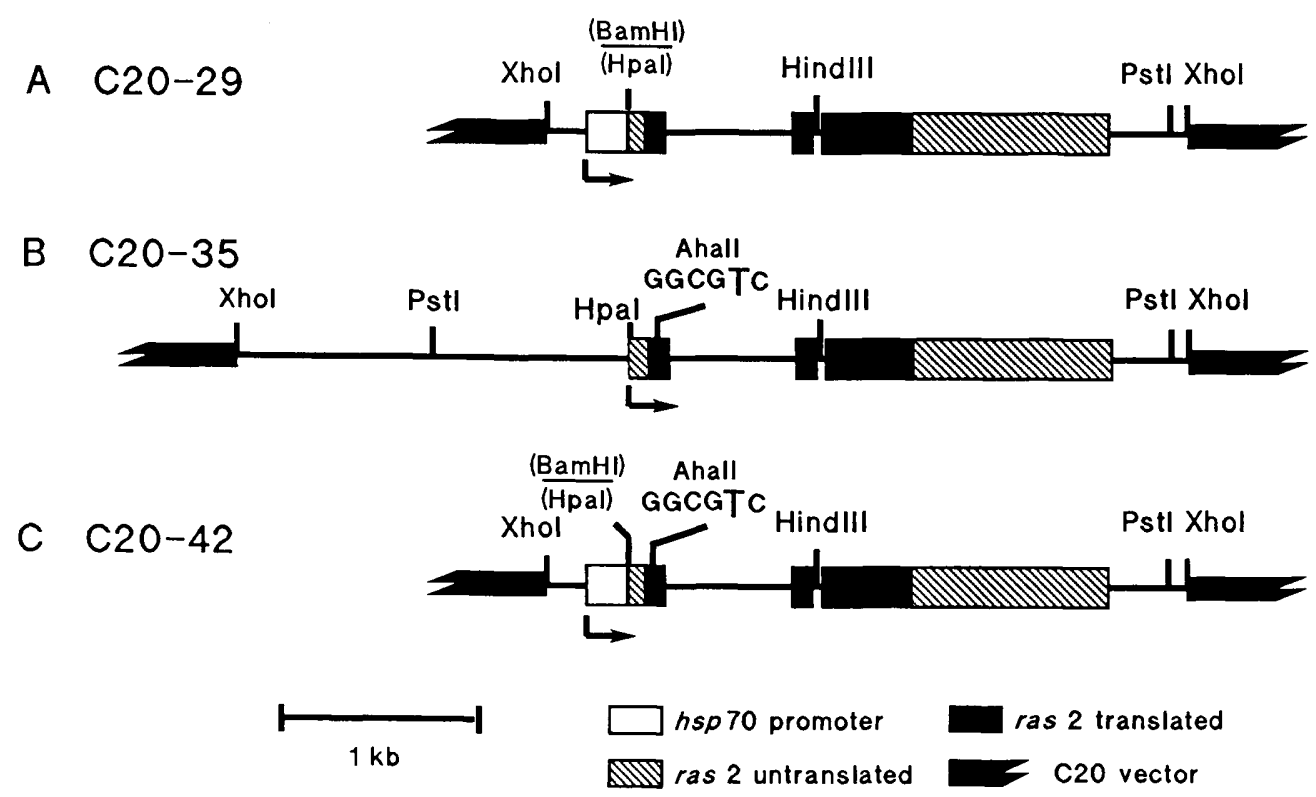

Figure 3. ras 2 gene constructs used for germ line transformations. In each case, the ras gene was inserted into the Sall site of Carnegie20 $(\mathrm{C} 20)$ in an opposite transcriptional orientation to the rosy gene $(A) \mathrm{C} 20-29$. The ras 2 gene was coupled to the hsp70 promoter at a HpaI site located 83 nucleotides upstream of the initiation codon. (B) C20-35. The first exon of ras 2 was subjected to oligonucleotide-directed mutagenesis (Zoller and Smith 1983) to create the mutation of Gly $14 \rightarrow$ Vall4 and installed in pIBI20-Val144.6. The single base change is indicated as a large letter. The $X$ hoI fragment was then subcloned into C20 to yield C20-35. $(C) \mathrm{C} 20-42$. The hsp70 promoter was installed into pIBI20-Vall4-4.6 XhoI after the normal promoter was removed. The 3-kb fusion XhoI fragment in pIBI20-hsp70-ras $2^{\text {Val14 }}$ was then subcloned into C 20 .

Heat-shock promoted ras2 constructs C20-29 and C20. 42 in transgenic Drosophila were inducible by heat shock

The inducibility of the hsp70 promoter fusion constructs was measured by Northern blotting of RNA isolated from adults of the C20-29 and C20-42 transgenic lines before and after heat shock and probing with ras subclone pUC8-HB-1.2 kb. Total RNA was isolated from

Table 1. Drosophila ras2 germ line transformants

\begin{tabular}{|c|c|c|c|}
\hline Construct & Lines & Chromosome & Homozygous \\
\hline \multicolumn{4}{|c|}{ C20-29 ras2 gene with hsp70 promoter } \\
\hline & $29-95$ & 3 & yes \\
\hline & $29-6$ & $\mathrm{X}$ & yes \\
\hline & $29-7$ & 3 & yes \\
\hline & $29-16$ & $\mathrm{X}$ & yes \\
\hline \multicolumn{4}{|c|}{ C20-35 ras $2^{\text {Val } 14}$ gene with $2 \mathrm{~kb}$ normal promoter } \\
\hline & $35-3$ & 2 & yes \\
\hline & $35-7$ & 3 & yes \\
\hline & $35-14$ & $\mathrm{X}$ & yes \\
\hline & $35-20$ & $\mathrm{X}$ & yes \\
\hline & $35-1$ & 2 & no \\
\hline & $35-19$ & 3 & yes \\
\hline & $35-\mathrm{B} 2$ & 2 & no \\
\hline & 35-B6 & 3 & no \\
\hline \multicolumn{4}{|c|}{ C20-42 $\operatorname{ras} 2^{\text {Vall } 14}$ gene with hsp70 promoter } \\
\hline & $42 \mathrm{PG} 1-4 \mathrm{X}$ & $\mathrm{X}$ & yes \\
\hline & 42JGB3-A or D & 2 & yes \\
\hline & $42 P G 1-3$ & 3 & no \\
\hline
\end{tabular}

adults that were kept at $22.5^{\circ} \mathrm{C}$ or were heat shocked for one $\mathrm{hr}$ at $37.0^{\circ} \mathrm{C}$. The autoradiograph is shown in Figure 4. In the RNA samples from the heat shocked (shown as HS in Fig. 4) animals carrying hsp70-promoted ras genes, inducible transcripts were detected. Because rRNA comigrates with the major ras transcript and hinders transfer we could not estimate the actual degree of induction. The origin of the larger, inducible RNA transcript is unknown.

An S1 nuclease assay was developed to exploit the sequence differences between the endogenous ras 2 transcripts and the heat shock-fusion transcripts. The hsp70 promoter was expected to initiate transcripts $223 \mathrm{nu}$ cleotides upstream of the Hpal site where the hsp70 promoter was fused to the ras $2^{\text {val14 }}$ sequence in the C20-42 constructs as shown in Figure 5A. Endogenous ras 2 transcription was known to initiate upstream of this $\mathrm{HpaI}$ site from sequence analysis of the rascDNA2 clones. The 559-bp XhoI-AhaII fragment from pIBI20-

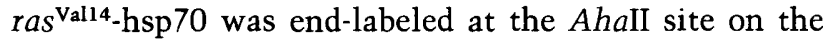
anti-sense strand. The cleavage site for Ahall was 122 nucleotides downstream from the $\mathrm{HpaI}$ junction site so that 122 bp protected fragments would be expected from endogenous ras 2 RNA and 345 bp fragments would be expected from hsp70-promoted transcripts (see Fig. 5A). Line C20-42PG1-4X was assessed for its ability to produce hsp 70 promoted transcripts upon heat induction by S1 nuclease protection experiments and the results are shown in Figure 5B. High levels of transcripts were observed after heat induction from the hsp70-ras $2^{\text {Val14 }}$ con- 


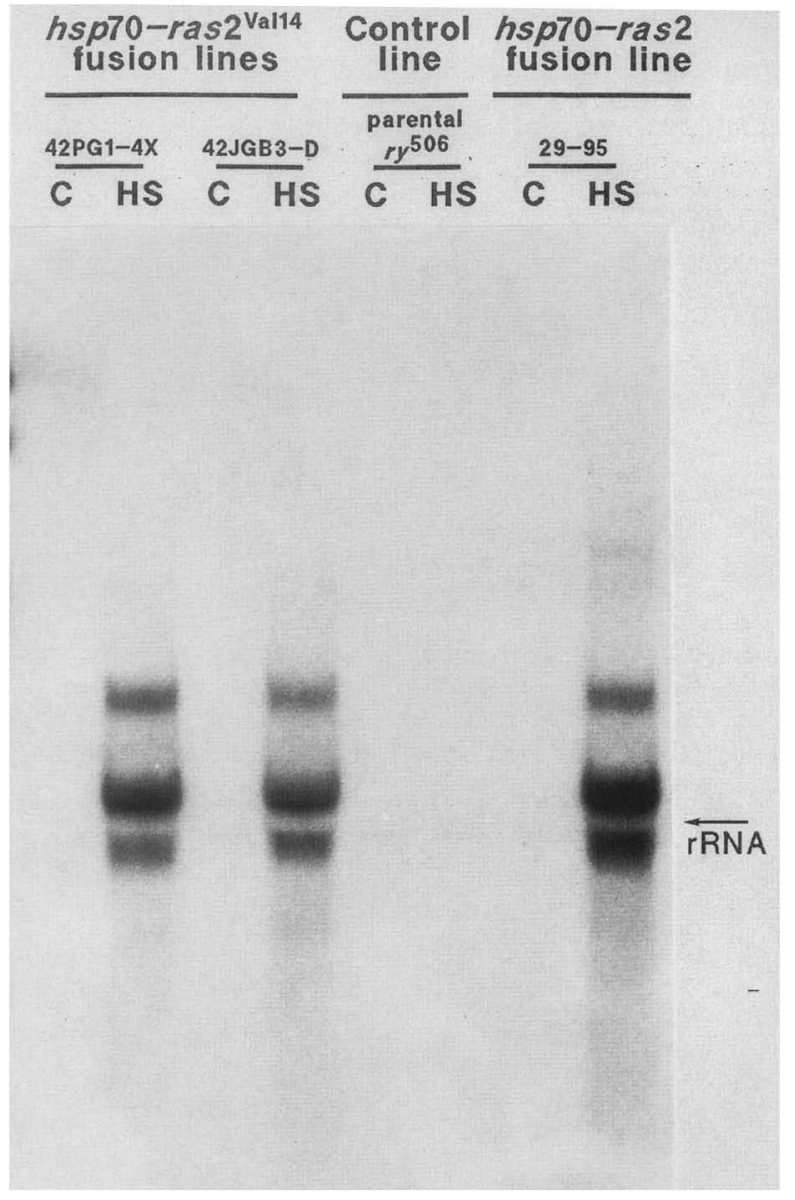

Figure 4. Northern blot of total control and heat shock RNA from hsp70-promoted ras 2 lines. Total RNA was isolated from whole adult flies subjected to $1-\mathrm{hr}$ heat pulse at $37.0^{\circ} \mathrm{C}(\mathrm{HS})$ or kept at $22.5^{\circ} \mathrm{C}(\mathrm{C})$. Six micrograms were loaded into each lane of a $1.25 \%$ formaldehyde gel, blotted, and probed with the 1.2 $\mathrm{kb}$ HindIII-BamHI fragment from pUC8-HB-1.2 kb representing most of the third exon of ras2. rRNA co-migrated with the lower ras transcript and interfered with the transfer.

struct as can be seen from the relative intensities of the 122-bp and 345-bp bands in lanes D and J. In fact, the endogenous ras 2 transcripts in the parental line $r y^{506}$ were nearly undectable and are best detected in lane $G$ where three times the amount of RNA was used than in the other protection assays. A low level of transcription from the hsp70 promoter was seen in control animals (lane H) and had been observed for other hsp70 constructs (Steller and Pirotta 1985). The phenotypic aspects of this basal level of transcription will be discussed below.

\section{The hsp70-ras $2^{\text {Val14 }}$ construct caused developmental disturbances in both induced and uninduced animals; the hsp70-ras2 construct caused no observable disturbances}

The ras $2^{\text {vall } 4}$ gene driven by the hsp 70 promoter was introduced into three transgenic lines of the C20-42 series (see Table 1). Initial observations indicated each of these stocks had low fertility, laying many eggs that failed to hatch, and showed developmental disturbances in their wing and eye structures even when kept at $18^{\circ} \mathrm{C}$ or $22.5^{\circ} \mathrm{C}$ throughout their entire development. Bristle formation was also affected in that the bristles were of variable size and placement. This was particularly noticeable on the wing anterior margin. Sternopleural bristles, and humeral bristles of the thorax were often bent or forked. The cuticle region of the humerus was also pronounced in many of the flies. The basal level of transcription from the heat shock promoter seen in the S1 nuclease protection assay (see Fig. 5B) was presumably responsible. The fly compound eye was a particularly sensitive gauge because its orderly, almost crystalline, nature readily revealed subtle defects to the observer. Conversely, the C20-29 series of lines carrying the hsp70-promoted normal ras 2 gene appeared entirely unaffected when reared under the same temperature regimes.

In the next series of experiments, animals from each line bearing the hsp70-ras $2^{\text {val14 }}$ heat-inducible construct were studied for their sensitivity to high- levels of transcripts induced at defined and brief periods during their development. Animals were mass cultured and heat shocked a single time at $37.0^{\circ} \mathrm{C}$ for 1 or $2 \mathrm{hr}$ unless specified otherwise. This amount of time represents $0.5-1 \%$ of the generation time of $D$. melanogaster under these conditions. Adult flies, pupae, and larvae from each line and from the rosy ${ }^{506}$ control line were scored for visible phenotypes appearing daily over at least one generation time period. The wings of animals heat shocked during the third instar and pupal stages failed to fuse at the dorsal and ventral surfaces resulting in a bloated appearance to the wings. Wings were typically smaller and distorted; they were absent and thoraces were distorted in a low percentage of flies although usually on one side of the fly. The same phenotype resulted from a pulse of as short as $5 \mathrm{~min}$ at $37.0^{\circ} \mathrm{C}$; even heat pulses of $1 \mathrm{hr}$ at $35.0^{\circ} \mathrm{C}$ caused the unfused wing phenotype. The sensitive period for wing anomalies was found to be quite broad and spanned the early third instar to mid-pupal stages. Yet animals heat shocked earlier in their development rarely had wing defects.

The hsp70-ras $2^{\text {vall4 }}$ animals taken from the entire third instar stage of development and subjected to a 2-hr heat shock had an overall survivability of $20-40 \%$; the stage at which death occurred was highly variable ranging from within hours resulting in blackened larval carcasses, to 6 to 7 days later near or at adult emergence. However, almost all animals heat shocked in the narrower window of time from a few hours prior to the onset of pupariation and for a few hours thereafter never survived. These animals died as larvae and pupae with blackened masses developing within the pupae in various sites; the larval mid-intestine and gastric ceca have often been identified as suffering this fate; however many other tissues were also affected ranging from missing abdominal structures to incompletely everting head tissue, grossly aberrant wings, and distorted legs.

Strikingly, in these animals bearing the hsp70-ras ${ }^{\text {val14 }}$ 

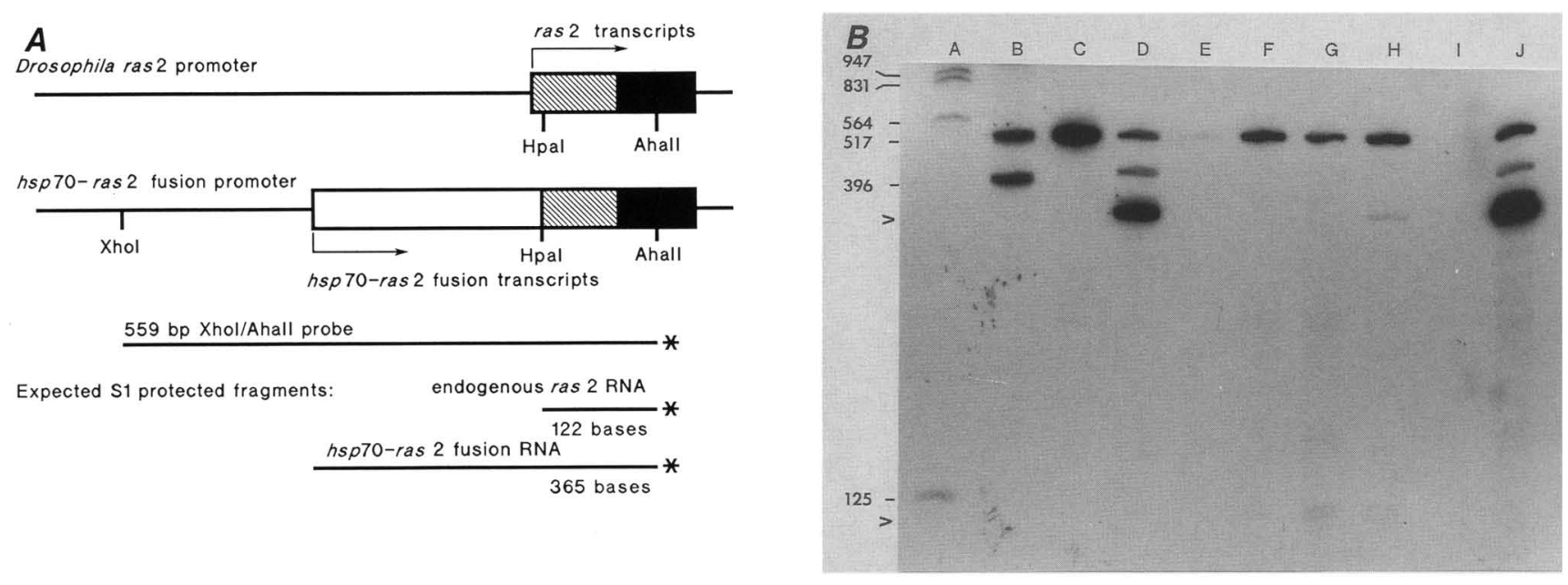

Figure 5. S1 nuclease protection analysis of endogenous and hsp70-promoted ras transcripts. $(A)$ Predicted fragments. $(B)$ Autoradiograph of the $S 1$ nuclease-protected fragments. (Lanes $A$ and $B$ ) Marker lanes, sizes are in nucleotides; (lane $C$ ) undigested probe; (lane $D$ ) C20-42PG1-4X heat shock RNA-protected fragments; (lane $E$ ) yeast RNA control; (lane $F$ ) control RNA from parental line ry ${ }^{506}$; (lane $G$ ) RNA from control ry ${ }^{506}$ flies $(150 \mu \mathrm{g})$; (lane $H$ ) control RNA from line C20-42PG 1-4X; (lane $I$ ) empty; (lane $I$ ) heat shock RNA from line C20-42PG1-4X.

construct, dorsal-to-ventral 'scars' developed in the middle-to-posterior portion of the adult eye when the animals were heat pulsed from 1 to 2 days before the onset of pupariation (late-third instar stage). Nearly all animals that developed to pharate adults or actually eclosed developed these scars bilaterally. Scars were observed in the late pupal stages as unpigmented regions of the eye visible through the pupal case or upon dissection. The scars consisted of unpigmented, irregular, and fused ommatidia as shown in Figure $6 \mathrm{C}$ and $\mathrm{D}$. The adult shown in Figure 6D was heat shocked from 22 to $24 \mathrm{hr}$ before pupariation; animals heat shocked earlier in the third instar stage developed scars more posterior to those shown in Figure 6C and D. Control adults of the parental stock $r y^{506}$ never displayed any phenotypic effects from heat shock pulses of $2 \mathrm{hr}$, during any portion of their development, when incubations were kept exactly at $37.0^{\circ} \mathrm{C}$. Heat pulses of $1 \mathrm{hr}$ to animals of the C20-42 line bearing the hsp-ras $2^{\text {Val14 }}$ construct caused less severe scarring (see Fig. 6B) and pulses of less than $30 \mathrm{~min}$ failed to produce scars. Using the optical neutralization technique, observations of adult eye photoreceptor patterns in animals heat shocked during development and bearing roughened eyes indicate that often the ommatidia were fused resulting in ommatidia of twice normal size. Where photoreceptors could be identified, two juxtaposed sets of photoreceptors were found and each set was composed of the proper number /data not shown). The technique is limited and does not detect absent photoreceptor clusters. This would indicate that the pigment cells in these fused ommatidia failed to develop or, move properly, to optically insulate each photoreceptor cluster resulting in two bundles of photoreceptors in one large ommatidium. The single lens that formed presumably results because the cone cells secreting the lens were able to compensate.

Somewhat surprisingly, high transient levels of normal ras 2 transcripts were tolerated well in the heat- shocked lines bearing hsp70-ras 2 constructs. No visible phenotyic resulted and $98-100 \%$ of the animals subjected to a single $2 \mathrm{hr}$ heat survived with no discernible ill effects. The same result was observed in animals of the control line $r y^{506}$.

The ras $2^{\text {Val14 }}$ gene driven by the endogenous ras2 promoter caused developmental disturbances similar to those seen with the hsp70 promoter

The developmental growth disturbances seen in the hsp70-ras $2^{\text {Vall4 }}$ animals may represent the accumulation of ras $2^{\mathrm{Vall}} \mathbf{4}$ transcripts in tissues that never express ras 2 since the hsp 70 promoter is active in all or almost all the tissues of the fly, whereas ras 2 was seen to be expressed in a temporal and tissue-specific manner (Segal and Shilo 1986). We could test if the animals were sensitive to low levels of ras $2^{\text {val14 }}$ by utilizing a construct with 2 $\mathrm{kb}$ of upstream sequences from the endogenous ras 2 gene. In this way, low levels of ras $2^{\text {val14 }}$ product would be produced in presumably the same tissues as the normal ras 2 product. These animals could then be compared to the uninduced hsp70-ras $2^{\text {vall4 }}$ flies to see if any of the growth disturbances were shared or dissimilar. We assumed that the controlling sequences for proper levels of ras 2 transcription map quite close to the gene since (as shown above) different unrelated transcripts were encoded within $1 \mathrm{~kb}$ of the upstream regions from ras 2 . The inclusion of $2 \mathrm{~kb}$ of upstream sequences would most probably allow proper transcription of the ras 2 construct. Since we had previously seen that even high levels of the normal ras 2 transcripts induced by heat shocks had failed to yield any phenotypes, we presumed that low levels being driven from the endogenous ras 2 promoter would have no effect on growth or fertility. No phenotype had been associated with lines bearing the hsp70-promoted normal ras 2 construct whether induced 

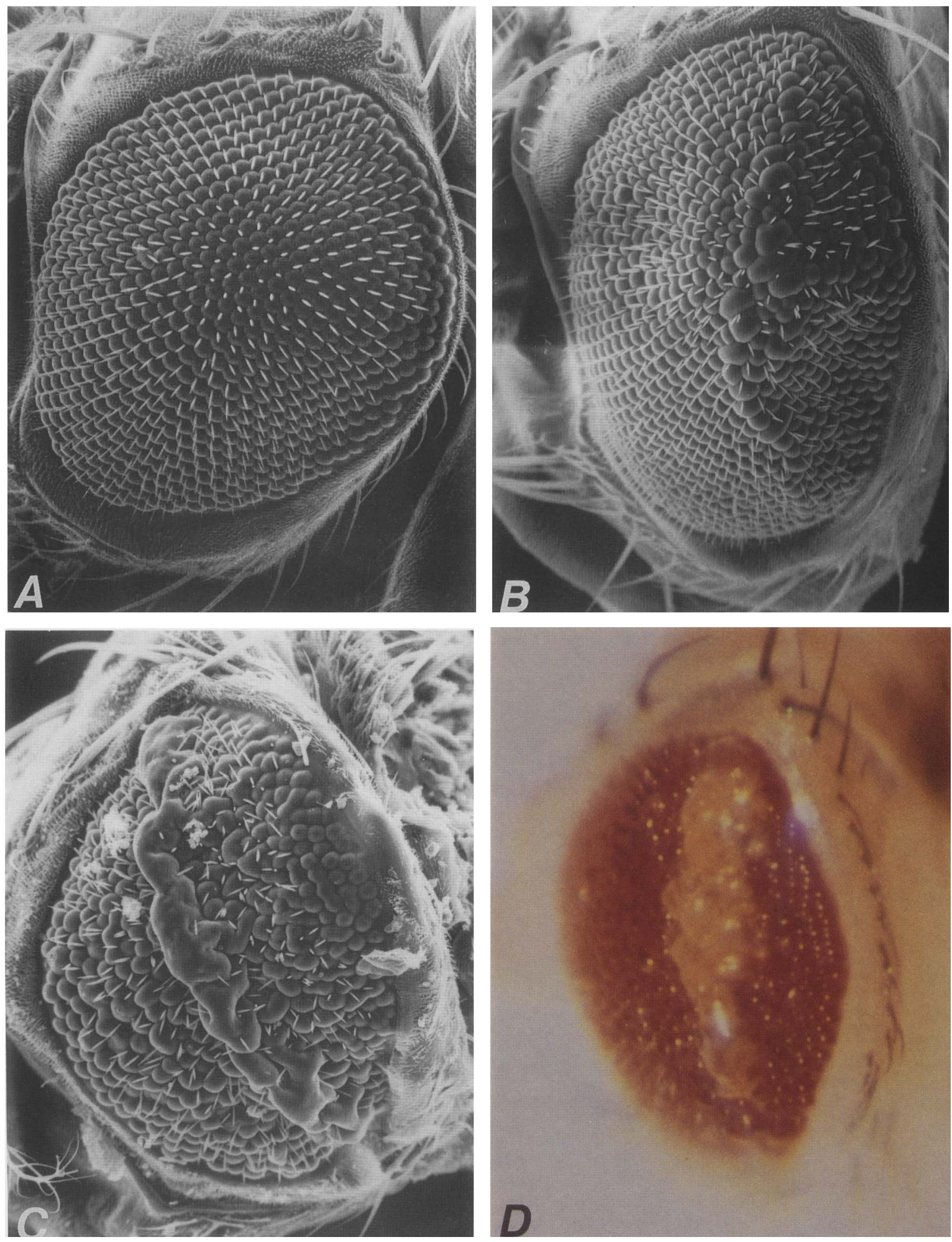

Figure 6. Phenotypes of the ras $2^{\text {val14 }}$ transformants. Anterior is to the left and dorsal is at the top. $(A)$ Scanning electron micrograph (SEM) of a wild-type adult Drosophila eye. (B) SEM of an adult eye from line $42 \mathrm{PG} 1-4 \mathrm{X}$ heat shocked $1 \mathrm{hr}$ at $37.0^{\circ} \mathrm{C}$ during the third instar developmental stage. $(C)$ SEM of an adult from line $42 \mathrm{PG} 1-4 \mathrm{X}$ heat-shocked for $2 \mathrm{hr}$ at $37.0^{\circ} \mathrm{C}$ during third instar stage. $(D)$ Light micrograph of adult from line 42JGB3-A heat shocked $2 \mathrm{hr}$ at $37.0^{\circ} \mathrm{C}$ during the third instar stage 22 to $24 \mathrm{hr}$ before pupa formation. 
with heat shocks or from the basal level of transcription from the hsp70 promoter.

The eight lines carrying the construct $\mathrm{C} 20-35$, i.e., the $2 \mathrm{~kb}$ of endogenous sequences upstream of ras 2 driving a mutated ras $2^{\mathrm{Vall}} 14$ gene, did display developmental anomalies, albeit to different degrees. All lines showed reduced viability and fertility, especially when made homozygous, of a similar nature to the hsp70-promoted ras $2^{\text {Val14 }}$ construct bearing lines of the $\mathrm{C} 20-42$ series. The gene-dosage effect was also seen in trans-heterozygotes derived from crosses between lines $\mathrm{C} 20-35-7$ and C20-35-14 as well as lines C20-35-7 and C20-35-3, indicating that the reduced viability and poor development resulted from the levels of $\operatorname{ras} 2^{\text {val14 }}$ and not solely the position of insertion. Typically, the wings of most of the flies developed poorly. They were held outstretched and the ventral and dorsal surfaces of the wing failed to fuse, often blackening as the flies aged. Ommatidia of the eyes were slightly disordered making the eyes rough in appearance in the majority of the individuals of the most severely affected lines; again, this was similar to the phenotype observed in the most affected flies from the uninduced hsp70-promoted ras $2^{\text {val14 }}$ lines. Lines C20-35-7 and C20-35-14 were weak, slow in movement, and showed a complete loss of wing beating whereas individuals of line C20-35-20 retained a diminished ability suggesting the construct was susceptible to position effects. This poor wing movement phenotype was more severe than the similar phenotype seen in the animals from the noninduced hsp70-promoted ras $2^{\text {Vall } 4}$ lines. In addition, the bristle formation on the wing and thorax, and the protruding cuticle growth of the humeral region observed in lines of the C20-35 series resembled phenotypes observed in the uninduced $\mathrm{C} 20-42$ series bearing the hsp70-ras $2^{\text {Val14 }}$ construct.

\section{Discussion}

Transient high levels of normal ras 2 transcripts produced in the heat-inducible $\mathrm{C} 20-29$ lines, or the low basal levels produced in uninduced flies, do not seem to have any deleterious effects on the flies.

On the other hand, high levels of ras $2^{\text {val14 }}$ transcripts induced in animals carrying the heat shock-inducible constructs (C20-42 series) caused a wide range of developmental anomalies. The low levels expressed basally from the uninduced hsp 70 promoter driving ras $2^{\text {vall }}$ also caused developmental anomalies of a much lesser degree, which appeared to be quite similar to the aberrant phenotypes seen in animals carrying the normal ras 2 promoter driving ras $2^{\text {vall } 14}$. The heat shock-inducible phenotypes may represent the primary effects of the expression of the ras $2^{\text {vall4 }}$ gene in the visibly affected tissues, although the phenotypes could be caused by transcription in tissues which then influences the tissues we see disrupted. When the hsp70-promoted ras $2^{\text {vall4 }}$ construct lines were reared at $18^{\circ} \mathrm{C}$ or $22.5^{\circ} \mathrm{C}$, they did show low fertility, poor wing development, and subtle defects in the eye. Also, bristle malformation was particularly noticeable on the wing anterior margin. Be- cause we see similar phenotypes in animals with the endogenous promoter, i.e., $2 \mathrm{~kb}$ of upstream sequences from the endogenous ras 2 locus, we feel that the phenotypes result from the sensitivity of those tissues normally expressing ras transcripts, although we have no proof to demonstrate that the $2 \mathrm{~kb}$ of upstream sequences are sufficient for proper tissue and temporal regulation of ras transcripts. Ostensibly, the ras 2 promoter in the constructs might be truncated or altered in some way that resulted in a release from the normal transcriptional regulation of ras 2 causing it to mimic the hsp70 promoter. A more likely consequence of such a truncation would be the down-regulation of transcription resulting in the absence of any discernible phenotype. Since phenotypes were observed the promoter must be active and is probably functioning in a normal manner.

We have chosen to focus on the eye phenotype because the development of the Drosophila eye has been well studied both genetically and ultrastructurally, and the eye consists of a relatively small number of different cell types. During the third instar and early pupal stages, a wave of photoreceptor cell differentiation visible as a morphogenic furrow, moves across the eye imaginal disc from the posterior to the anterior margin (Ready et al. 1976). Clusters of photoreceptor cells form initially; later cone, pigment, and hair nerve cells are added sequentially to form an ommatidium made up of 22 cells (Ready et al. 1976; Tomlinson and Ready 1987). Genetic analysis of clones and observations of eye development at the cellular level indicate that the cells forming the ommatidia differentiate using positional cues to guide their decisions (Ready et al. 1976; Lawrence and Green 1979; Tomlinson and Ready 1987). To explain the disordered development of the eye that results from the high levels of ras $2^{\text {val14 }}$ in light of the prevailing models for ras function, we might presume that the phenotype arises because of the aberrant transduction of a signal across the membrane of the eye cells. This signal serves to cue the cells to adopt their appropriate morphology. A considerable number of models are also likely. The dorsalto-ventral scar could result from a disruption in the transduction of extracellular signals by the photoreceptor cells as they begin to differentiate, arresting or altering their development. Alternatively, the photoreceptors may fail to elaborate the proper positional cues needed by neighboring cells of the pigment or cone cell types that undergo subsequent differentiation (Tomlinson and Ready 1987). Analysis of the third instar larval eye discs for photoreceptor patterning, as well as the pupal eye discs, when the pigment and cone cells are moving into position and differentiating, from hsp70ras $2^{\text {Val14 }}$ animals that are heat shocked in the larval stage may allow us to identify the particular cell types that appear sensitive to ras levels. The sensitivity of the eye to ras $2^{\text {val14 }}$ expression is interesting in view of recent work indicating signal transduction via a membrane-associated tyrosine kinase molecule as a cue for photoreceptor differentiation. Sevenless, as eye-specific gene (Harris et al. 1976), when mutant, causes the seventh photoreceptor neuron to become homeotically trans- 
formed into a nonneuronal cone cell. Sevenless encodes a putative tyrosine kinase present at the cell membrane (Baneriee et al. 1987; Hafen et al. 1987). Perhaps the product of ras 2 is a downstream molecule involved in this or other transduction events occurring during the differentiation of the eye.

Two genes have been identified that influence the adult phenotype of the eye during the same development time period and cause a dorsal-to-ventral scar; X-rays can cause similar scars (Becker 1957). An allele of Notch (Foster and Suzuki 1970), which encodes a membrane protein with homology to epidermal growth factor (Wharton et al. 1985; Kidd et al. 1986), and an allele of Shibere (Poodry et al. 1973), thought to be deficient in membrane recycling (Kim and $\mathrm{Wu}$ 1987), develop a dorsal-to-ventral scar of the adult eye if the third instar larvae when reared at the nonpermissive temperature for a period of several hours. A dorsal-to-ventral scar that is lacking pigmentation (see Fig. 6D) as seen with the ras $2^{\text {Val14 }}$ mutation has not, to our knowledge, been described before and suggests to us that dorsal-to-ventral scars may be formed in a variety of ways. Henkemeyer et al. (1987) have found that the Abelson proto-oncogene (abl) of Drosophila, when mutant, causes the retinal pattern of the adult eye to be disrupted and retinal cells are often missing and ommatidia can fuse. Experiments are now in progress to investigate possible interaction among ras $2^{\text {valli }}$, Notch, and sevenless alleles.

The particular pattern of tissue sensitivity of ras $2^{\text {val14 }}$ expression in Drosophila is correlated to the presence of high levels of endogenous ras expression in the particular organs of the developing fly (Segal and Shilo 1986) but is limited to a subset of these tissues. In particular, the tissues in the larval stages that are proliferating, the imaginal discs, gonads, and brain, express each of the ras genes. In the adult, the ovaries and the terminally differentiated cortex of the brain and ganglia express ras transcripts (Segal and Shilo 1986). Our results indicate that the eye and wing primordia are particularly sensitive to ras $2^{\text {vall4 }}$ expression. The low fertility of the females may reflect the expression of mutant ras 2 in the ovaries which normally produce high levels of ras transcripts (Segal and Shilo 1986). In Drosophila, as also shown in the mouse (Sinn et al. 1987), there appear to be specific tissues in which an activated ras gene is mute and others in which gross developmental anomalies occur. This may result from the fact that the different forms of ras play different roles in the separate tissues; alternatively, ras proteins may play unequal roles in the development of each of the tissues (Sinn et al. 1987).

It will be interesting to see to what degree other protooncogenes that have been described in Drosophila (reviewed in Shilo 1987) will affect development when mutated and transformed into the germ line of Drosophila. The lines developed in this study could then be used to study possible synergistic interactions among oncogenes as has been done in mice (Sinn et al. 1987). The nature of the molecules that interact with ras proteins and the mechanisms of their actions are at present unknown in multicellular organisms. These mutant lines will be the starting material for a genetic screen to isolate revertants in the ras 2 phenotypes caused by second-site mutations; these mutations should identify genes involved with ras functioning.

\section{Materials and methods}

Preparation of nucleic acids, genomic and cDNA library screening, and DNA sequencing

Plasmid DNA isolations, ligations, and gene library screens were done by standard methods (Maniatis et al. 1982). Total RNA was extracted from adult Drosophila using the SDSphenol technique of Spradling and Mahowald (1979). The cDNA clones were isolated from the Kauvar library (Poole et al. 1985). Denaturing formaldehyde gels were used for RNA gels (Maniatis et al. 1982) and RNA transfers were to nylon membranes (ICN Biotrans). DNA sequencing and end-labeling were done by the methods of Maxam and Gilbert (1980).

\section{Constructs and oligonucleotide-directed mutagenesis}

C20-29: An XhoI-BamHI fragment of 437 bp from the Drosophila hsp70 promoter containing sequences from -194 to +223 was isolated from pVC8-1 (V. Corces, unpubl.), filled in at the BamHI site and used to replace the $5^{\prime} \mathrm{XhoI-HpaI}$ fragment containing the normal ras 2 promoter in pIBI20-4.6XhoI to create pIBI20-hsp70-ras2. Its $3.0 \mathrm{~kb}$ Xhol fragment was subcloned into Carnegie20 to make C20-29.

C20-35: The HpaI-HindIII fragment from pIBI20-4.6Xhol containing the first and second exons of ras 2 was subcloned into pIBI20. Oligonucleotide-directed mutagenesis was performed as described (Zoller and Smith 1983). The single base change creating the mutation at codon 14 of ras 2 is underlined in the oligonucleotide sequence GCGGCGTCGGCGTGGGCA. The oligonucleotide spans positions $\overline{121-138}$ in Figure 2 and was annealed to the single-stranded DNA from pIBI20-HpaI-HindIII. Screening of mutant clones was done with the end-labeled oligonucleotide on DNA isolated from single colonies and spotted onto nitrocellulose. One putative clone was sequenced to verify the presence of the mutation which creates an AhaII site. The mutated HpaI-HindIII fragment was inserted in place of the wild-type fragment to create pIBI20-Val14-4.6Xhol and the XhoI fragment was inserted into C20.

C20-42: The XhoI-BamHI hsp70 promoter was installed into pIBI20-Val14-4.6XhoI after the 2-kb 5' XhoI to HpaI fragment was removed by complete digestion with $\mathrm{HpaI}$ followed by partial digestion with XhoI. The 3-kb fusion XhoI fragment in pIBI20-hsp70-ras $2^{\text {val14 }}$ was then subcloned into C20.

\section{S1 nuclease protection assay}

The 559 bp XhoI-AhaII fragment from pIBI20-hsp70-ras $2^{\text {val14 }}$ was end-labeled at the $A$ hall site on the anti-sense strand. Endlabeled probe $\left(50 \mathrm{ng}\right.$ ) was hybridized overnight at $46^{\circ} \mathrm{C}$ in $\mathrm{S} 1$ hybridization buffer (Maniatis et al. 1982) to $50 \mu \mathrm{g}$ (with the exception of lane $\mathrm{G}$ which contained $150 \mu \mathrm{g}$ ) of total RNA isolated from adult flies that had been reared at $22.5^{\circ} \mathrm{C}$ (controls) or kept at $37.0^{\circ} \mathrm{C}$ for $1 \mathrm{hr}$ (heat shocked). After S1 nuclease digestion of the hybrids, the nucleic acids were recovered by ethanol precipitation and loaded on a $5 \%$ denaturing acrylamide gel (Maniatis et al. 1982). Unless otherwise indicated, all heat shocks were performed at $37.0^{\circ} \mathrm{C}$ by immersing vials containing flies of varying stages in a Lauda water bath. 


\section{Electron microscopy and optical neutralization of eyes}

For electron microscopy, fly heads were fixed in $4 \%$ glutaraldehyde in $0.1 \mathrm{M} \mathrm{Na}$ cacodylate $(\mathrm{pH} 7.0)$, critical point dried, coated, and examined in a JOEL scanning electron microscope.

The optical neutralization technique as described by Banerjee et al. (1987) was used with slight modification. Fly heads were severed with a razor blade and immediately glued to microscope slides with a small drop of cyanoacrylate adhesive (Wonderbond, Borden, Inc). The heads were immediately covered with immersion oil to prevent drying and loss of retinal detail and viewed with a $40 \times$ or $63 \times$ objective.

\section{Acknowledgments}

We thank Drs. P. Geyer for help with embryo injection, S. Parkhurst for Figure 6A, and R. Marlor for a portion of the genomic DNA sequencing. We thank Dr. M. Sepanski of the Carnegie Institute for assistance with electron microscopy, and Drs. R. Cagan, R. Lebovitz, and D. Ready for helpful guidance and discussions. We are grateful to Drs. L. Kauvar and T. Kornberg for furnishing the Drosophila cDNA library and T. Maniatis and J. Lauer for providing the Canton $S$ genomic library. This work was supported by PHS grant CA40540.

\section{References}

Andres, A.C., C.A. Schonenberger, B. Groner, L. Hennighausen, M. LeMeur, and P. Gerlinger. 1987. Ha-ras oncogene expression directed by a milk protein gene promoter : tissue specificity, hormonal regulation, and tumor induction in transgenic mice. Proc. Nat1. Acad. Sci. 84: 1299-1303.

Banerjee, U., P.J. Renfranz, J.A. Pollock, and S. Benzer. 1987. Molecular characterization and expression of sevenless, a gene involved in neuronal pattern formation in the Drosophila eye. Cell 49: 281-291.

Bar-Sagi, D. and J.R. Feramisco. 1985. Microinjection of the ras oncogene protein into $\mathrm{PCl} 2$ cells induces morphological differentiation. Cell 42: 841-848.

. 1986. Induction of membrane ruffling and fluid phase pinocytosis in quiescent fibroblasts by ras proteins. Science 233: $1061-1068$.

Barbacid, M. 1987. ras Genes. Annu. Rev. Biochem. 56: 779827.

Becker, H.J. 1957. Uber Röntgenmosaikflecken und Defektmutation am Auge von Drosophila und die Entwicklungsphysiologie des Auges. Z. Induk. Abst. Vererb. Lehre. 88: 333373.

Bos, J.L., E.R. Fearson, S.R. Hamilton, M. Verlaan-de Vries, J.H. van Boom, A.J. van der Eb, and B. Vogelstein. 1987. Prevalence of ras gene mutations in human colorectal cancers. Nature 327: 293-297.

Chesa, P.G., W.J. Rettig, M.R. Melamud, L.J. Old, and H.L. Nimam. 1987. Expression of $2^{1} 1^{\text {ras }}$ in normal and malignant human tissues: Lack of association with proliferation and malignancy. Proc. Natl. Acad. Sci. 84: 3224-3234.

Chipperfield, R.G., S.S. Jones, K.-M. Lo, and R.A. Weinberg. 1985. Activation of Ha-ras p21 by substitution, deletion, and insertion mutations. Mol. Cell. Biol. 5: 1809-1818.

Corden, J., B. Wasylyk, A. Buchwalder, P. Sassone-Corsi, C. Kedinger, and P. Chambon. 1980. Promoter sequences of eukaryotic protein-coding genes. Science 209: 1406-1414.

Forrester, K., C. Almoguera, K. Han, W.E. Grizzle, and M. Perucho. 1987. Detection of high incidence of K-ras oncogenes during human colon tumorigenesis. Nature 327: 298-303.

Foster, G.G. and D.T. Suzuki. 1970. Temperature-sensitive mutations in Drosophila melanogaster. IV. A mutation affecting eye facet arrangement in a polarized manner. Proc. Nat1. Acad. Sci. 67: 738-745.

Gibbs, J.B., I.S. Sigal, M. Poe, and E.M. Scolnick. 1984. Intrinsic GTPase activity distinguishes normal and oncogenic ras p21 molecules. Proc. Natl. Acad. Sci. 81: 5704-5708.

Guerrero, I., A. Villasante, V. Corces, and A. Pellicer. 1984. Activation of a c-K-ras oncogene by somatic mutation in mouse lymphomas induced by gamma radiation. Science 225: 1159-1162.

Hafen, E., K. Basler, J.E. Edstroem, and G.M. Rubin. 1987. Sevenless, a cell specific homeotic gene of Drosophila encodes a putative transmembrane receptor with a tyrosine kinase domain. Science 236: 55-63.

Harris, W.A., W.S. Stark, and J.A. Walker. 1986. Genetic dissection of the photoreceptor system in the compound eye of Drosophila melanogaster. J. Physiol. 256: 415-439.

Henkemeyer, M.J., F.B. Gertler, W. Goodman, and F.M. Hoffmann. 1987. The Drosophila Abelson proto-oncogene homolog: identification of mutant alleles that have pleiotropic effects late in development. Cell 51: 821-828.

Hurley, J.B., M.I. Simon, D.B. Teplow, J.D. Robishaw, and A.G. Gilman. 1984. Homologies between signal transducing $G$ proteins and ras gene products. Science 226: 860-862.

Kataoka, T., S. Powers, C. McGill, O. Fasano, J. Strathern, J. Broach, and M. Wigler. 1984. Genetic analysis of yeast $R A S 1$ and RAS2 genes. Cell 37: 437-445.

Kidd, S., M.R. Kelley, and M.W. Young. 1986. Sequence of the Notch locus of Drosophila melanogaster: Relationship of the encoded protein to mammalian clotting and growth factors. Mol. Cell. Biol. 6: 3094-3108.

Kim, Y.T. and C.F. Wu. 1987. Reversible blockage of neurite development and growth cone formation in neuronal cultures of a temperature-sensitive mutant of Drosophila. I. Neurosci. 7: 3245-3255.

Lawrence, P.A. and S.M. Green. 1979. Cell lineage in the developing retina of Drosophila. Dev. Biol. 71: 142-152.

Lochrie, M.A., J.B. Hurley, and M.I. Simon. 1985. Sequence of the alpha subunit of photoreceptor $G$ protein: homologies between transducin, ras, and elongation factors. Science 228: 96-99.

Maniatis, T., R.C. Hardison, E. Lacy, J. Lauer, C. O'Connell, D. Quon, G.K. Sim, and A. Efstratiadis. 1978. The isolation of structural genes from libraries of eukaryotic DNA. Cell 15: $687-701$.

Maniatis, T., E.F. Fritsch, and J. Sambrook. 1982. Molecular cloning: A laboratory manual. Cold Spring Harbor Laboratory, New York.

Manne, V., E. Bekesi, and H.F. Kung. 1985. Ha-ras proteins exhibit GTPase activity: Point mutations that activate Ha-ras gene products result in decreased GTPase activity. Proc. Natl. Acad. Sci. 82: 376-380.

Maxam, A.M. and W. Gilbert. 1980. Sequencing end-labeled DNA with base specific chemical cleavages. Methods Enzymol. 65: 499-560.

McGrath, J.P., D.J. Capon, D.V. Goeddel, and A.D. Levinson. 1984. Comparative biochemical properties of normal and activated human ras p2l protein. Nature 310: 644-649.

Mozer, B., R. Marlor, S. Parkhurst, and V. Corces. 1985. Characterization and developmental expression of a Drosophila ras oncogene. Mol. Cell. Biol. 5: 885-889.

Neuman-Silberberg, F.S., E. Schejter, F.M. Hoffmann, and B.-Z. Shilo. 1984. The Drosophila ras oncogenes: Structure and nucleotide sequence. Cell 37: 1027-1033.

O'Connell, P. and M. Rosbash. 1984. Sequence, structure, and codon preference of the Drosophila ribosomal protein 49 gene. Nucleic Acids Res. 12: 5495-5513. 
Olsen, E.N., G. Spizz, and M.A. Tainsky. 1987. The oncogenic forms of $\mathrm{N}$-ras and $\mathrm{H}$-ras prevent skeletal myoblast differentiation. Mol. Cell. Biol. 7: 2104-2111.

Poodry, C.A., L. Hall, and D.T. Suzuki. 1973. Developmental properties of Shibere ${ }^{t s 1}$ : a pleiotropic mutation affecting larval and adult locomotion and development. Dev. Biol. 32: 373-386.

Poole, S.J., L.M. Kauvar, B. Drees, and T. Kornberg. 1985. The engrailed locus of Drosophila: Structural analysis of an embryonic transcript. Cell 40: 37-43.

Proudfoot, N.J. and G.G. Brownlee. 1976. 3' Non-coding region sequences in eukaryotic messenger RNA. Nature 263: $211-$ 214.

Quaife, C.J., C.A. Pinkert, D.M. Ornitz, R.D. Palmiter, and R.L. Brinster. 1987. Pancreatic neoplasia induced by ras expression in acinar cells of transgenic mice. Cell 48: 1023-1034.

Ready, D.F., T.E. Hanson, and S. Benzer. 1976. Development of the Drosophila retina, a neurocrystalline lattice. Dev. Biol. 53: $217-240$.

Reymond, C.D., R.H. Gomer, W. Nellen, A. Theibert, P. Devreotes, and R.A. Firtel. 1986. Phenotypic changes induced by a mutated ras gene during the development of Dictyostelium transformants. Nature 323: 340-343.

Rubin, G.M. and A.C. Spradling. 1983. Vectors for P elementmediated gene transfer in Drosophila. Nucleic Acids Res. 11: $6341-6351$.

Scolnick, E.M., A.G. Papageorge, and T.Y. Shih. 1979. Guanine nucleotide-binding activity as an assay for $s r c$ protein of ratderived murine sarcoma viruses. Proc. Natl. Acad. Sci. 76: 5355-5359.

Seeburg, P.H., W.W. Colby, D.J. Capon, D.V. Goeddel, and A.D. Levinson. 1984. Biological properties of human c-Ha-ras 1 genes mutated at codon 12. Nature 312: 71-75.

Segal, D. and B.Z. Shilo. 1986. Tissue localization of Drosophila melanogaster ras transcripts during development. Mol. Cell. Biol. 6: 2241-2248.

Shilo, B.Z. 1987. Proto-oncogenes in Drosophila melanogaster. Trends Genet. 3: 69-72.

Sinn, E., W. Muller, P. Pattengale, I. Teppler, R. Wallace, and P. Leder. 1987. Coexpression of MMTV/v-Ha-ras and MMTV/ c-myc genes in transgenic mice: synergistic action of oncogenes in vivo. Cell 49: 465-475.

Spandidos, D.A. and N.M. Wilkie. 1984. Malignant transformation of early passage rodent cells by a single mutated human oncogene. Nature 310: 469-475.

Spradling, A.C. and A.P. Mahowald. 1979. Identification and genetic localization of mRNAs from ovarian follicle cells of Drosophila melanogaster. Cell 16: 589-598.

Steller, H. and V. Pirotta. 1985. A transposable P vector that confers selectable G418 resistance to Drosophila larvae. EMBO I. 4: 167-171.

Sweet, R.W., S. Yokoyama, T. Kamata, J.R. Feramisco, M. Rosenberg, and M. Gross. 1984. The product of ras is a GTPase and the T24 oncogenic mutant is deficient in this activity. Nature 311: 273-275.

Tanabe, T., T. Nukuda, Y. Nishikawa, K. Sugimoto, H. Suzuki, H. Takahashi, M. Noda, T. Haga, A. Ichiyama, K. Kangawa, N. Minamino, H. Matsua, and S. Numa. 1985. Primary structure of the $\alpha$-subunit of transducin and its relationship to ras proteins. Nature 315: 242-245.

Temeles, G.L., J.B. Gibbs, J.S. D'Alonzo, I.S. Sigal, and E.M. Scolnick. 1985. Yeast and mammalian ras proteins have conserved biochemical properties. Nature 313: 700-703.

Tomlinson, A. and D.F. Ready. 1987. Neuronal differentiation in the Drosophila ommatidium. Dev. Biol. 120: 336-376.

Wharton, K.A., K.M. Johansen, T. Xu, and S. Artavanis-Tsakonas. 1985. Nucleotide sequence from the neurogenic locus Notch implies a gene product that shares homology with proteins containing EGF-like repeats. Cell 43: 567581.

Willingham, M.C., I. Pastan, T.Y. Shih, and E.M. Scolnick. 1980. Localization of the src gene product of the Harvey strain of MSV to plasma membrane of transformed cells by electron microscopic immunocytochemistry. Cell 19: $1005-1014$.

Willumsen, B.M., A. Christensen, N.L. Hubbert, A.G. Papageorge, and D.R. Lowy. 1984. The p21 ras C-terminus is required for transformation and membrane association. $\mathrm{Na}$ ture 310: 583-586.

Zoller, M.J. and M. Smith. 1983. Oligonucleotide-directed mutagenesis of DNA fragments cloned into M13 vectors. Methods Enzymol. 100: 468-500. 


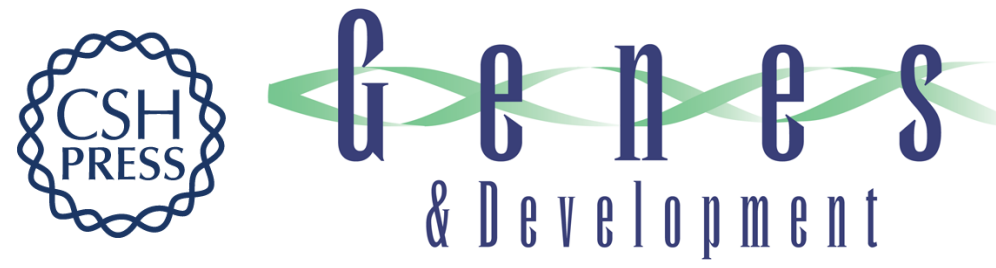

\section{Expression of an activated ras gene causes developmental abnormalities in transgenic Drosophila melanogaster.}

J G Bishop and V G Corces

Genes Dev. 1988, 2:

Access the most recent version at doi:10.1101/gad.2.5.567

References This article cites 54 articles, 18 of which can be accessed free at:

http://genesdev.cshlp.org/content/2/5/567.full.html\#ref-list-1

License

Email Alerting

Service

Receive free email alerts when new articles cite this article - sign up in the box at the top right corner of the article or click here.

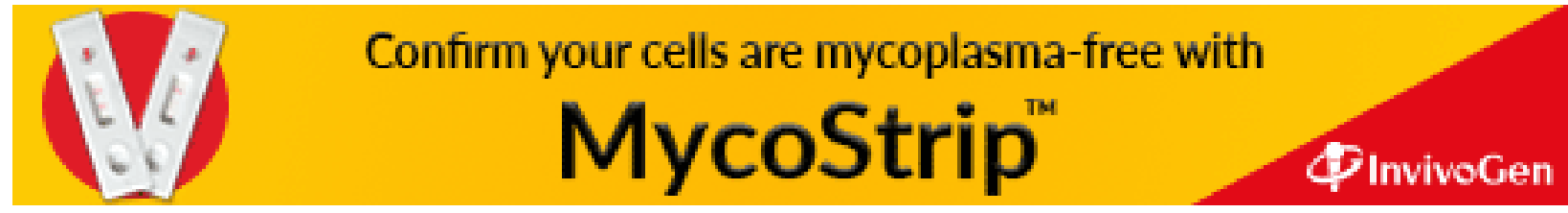

